\title{
Cytoreductive surgery combined with hyperthermic intrapleural chemotherapy to treat thymoma or thymic carcinoma with pleural dissemination
}

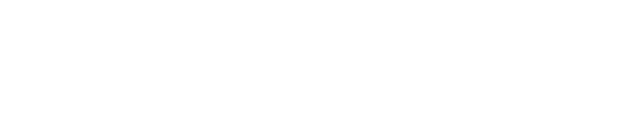

Lei Yu'

Yun Jing ${ }^{2}$

Shan $\mathrm{Ma}^{1}$

Fei $\mathrm{Li}^{\prime}$

Yun-Feng Zhang'

'Department of Thoracic Surgery, ${ }^{2}$ Department of Neurology, Beijing Tongren Hospital, Capital Medical University, People's Republic of China
Background: The treatment of thymoma or thymic carcinoma with pleural dissemination remains controversial due to the unpredictable natural history of this tumor. Our study discusses the combination of cytoreductive surgery with hyperthermic intrapleural chemotherapy to treat thymoma or thymic carcinoma with pleural dissemination.

Methods: From February 2008 to January 2010, there were four patients with pleural thymoma metastases undergoing cytoreductive surgery and intrathoracic hyperthermic perfusion with chemotherapy at our department. After video-assisted thoracoscopic surgery, the hyperthermic perfusion system was set up for hyperthermic intrapleural chemotherapy. The thoracic cavity was perfused at a speed of approximately $1.8-2.3 \mathrm{~L} / \mathrm{min}$ with $0.9 \%$ normal saline. The intrathoracic temperature remained between $42^{\circ} \mathrm{C}$ and $43^{\circ} \mathrm{C}$. The perfusion process lasted for 2 hours.

Results: There were no perioperative deaths. During the hyperthermic perfusion, the patient's core temperature varied from $36.3^{\circ} \mathrm{C}$ and $39.3^{\circ} \mathrm{C}$ and pulse varied from 59 beats $/ \mathrm{min}$ and 126 beats/min. Intraoperative sinus tachycardia occurred in two elderly patients. No hematologic toxicity and nephrotoxicity was observed within 1 week after surgery. Postoperative pneumonia occurred in one elderly patient. Patients were followed up for 1-4 years. One elderly patient died of heart failure 1 year after surgery. There were no patients with local recurrence or metastases to distant sites.

Conclusions: Cytoreductive surgery and intrathoracic hyperthermic perfusion with chemotherapy may be effective in treating thymoma or thymic carcinoma with pleural dissemination and has an encouraging impact on the patients' long-term survival.

Keywords: thymoma, pleural dissemination, surgery, hyperthermia, chemotherapy

\section{Introduction}

Thymomas are generally considered to have an indolent growth pattern, but are malignant because they show potential for local invasion, pleural dissemination, and even systemic metastases. Currently, most experts believe that surgical resection followed by radiation may produce good long-term results. However, Ogawa and colleagues found that postoperative radiation might prevent local recurrence, but was ineffective when pathologic pleural invasion or pleural dissemination was present. ${ }^{1}$ The treatment of pleural recurrent thymoma remains controversial due to the unpredictable natural history of this tumor. In the following, discussion has been made concentrating on our experience in cytoreductive surgery combined with hyperthermic intrapleural chemotherapy to treat thymoma or thymic carcinoma with pleural dissemination.
Department of Thoracic Surgery,

Beijing Tongren Hospital,

Capital Medical University,

No I Dongjiaominxiang Street,

Dongcheng District, Beijing City,

100730, People's Republic of China

Tel +86 I05826 85I3

Email yuleil I I8@sohu.com 
Table I Clinical profiles of four patients

\begin{tabular}{|c|c|c|c|c|c|c|c|}
\hline No & $\begin{array}{l}\text { Sex/age } \\
\text { (years) }\end{array}$ & $\begin{array}{l}\text { Recurrent } \\
\text { case }\end{array}$ & Side with metastases & PS & Complication & $\begin{array}{l}\text { Follow-up } \\
\text { (years) }\end{array}$ & Outcome \\
\hline I & Female/48 & Yes & Right & No & No & 4 & NETR \\
\hline 2 & Female/69 & Yes & Right (right lower lobe) & No & ST & 1.5 & NETR \\
\hline 3 & Male/52 & No & Left & Myasthenia gravis & No & 2.5 & NETR \\
\hline 4 & Female/68 & No & Left (pericardial effusion) & No & $\begin{array}{l}\text { ST } \\
\text { PP }\end{array}$ & 1.0 & $\begin{array}{l}\text { Death/heart } \\
\text { failure }\end{array}$ \\
\hline
\end{tabular}

Abbreviations: PS, paraneoplastic syndromes; NETR, no evidence of thymoma recurrence; PP, postoperative pneumonia; ST, intraoperative sinus tachycardia.

\section{Patients and methods}

\section{Patient population}

From February 2008 to January 2010, there were four patients with pleural thymoma metastases undergoing cytoreductive surgery and intrathoracic hyperthermic perfusion with chemotherapy at our department. The clinical profiles of patients are summarized in Table 1. Among them, two patients were recurrent cases, one patient had generalized myasthenia gravis, one having pericardial effusion, and one having a metastasis at the right lower lobe (Figure 1). Patients had a complete preoperative check-up, including physical examination, complete blood count, and liver function tests, renal function tests, cardiac ultrasound and electrocardiogram, chest X-ray, computed tomography (CT) scan, and so on. Preoperative CT revealed that thymoma metastases were resectable and limited to one pleural cavity. Patients were evaluated twice in the first year after surgery and at least once a year for the other years.

The study was approved by the Human Research Ethics Board of Beijing Tongren Hospital, Capital Medical University. Patients were warned of the potential risks prior to cytoreductive surgery and intrathoracic hyperthermic perfusion with chemotherapy, and signed consent forms if they agreed to undergo surgery.

\section{Surgical technique}

The hyperthermic perfusion system mainly consists of a reservoir, a temperature sensor, a heat exchanger, inflow and
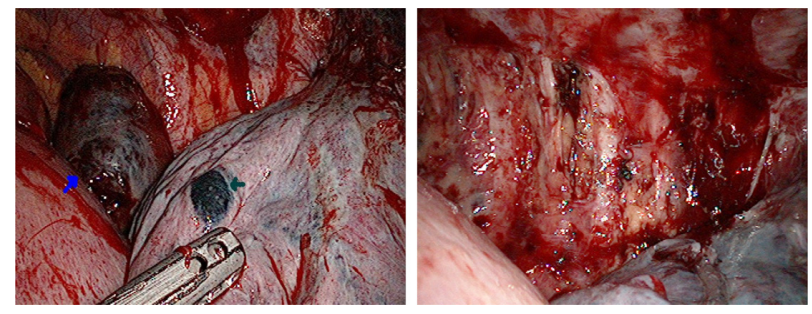

Figure I A recurrent thymoma with metastases at pleura and the right lower lobe (right) and after undergoing resection of sheets of pleura and wedge of lung, as well as intrathoracic hyperthermic perfusion with chemotherapy (left). outflow catheters, and a special pump, which automatically provides normal circulation during hyperthermic intrapleural chemotherapy and is different from the heart-simulating pump in that no oxygenator is used.

According to the recurrence or metastasis sites, video-assisted thoracoscopic surgery was performed through left or right approaches. After double-lumen intubation, the patient is placed in a lateral decubitus position and three trocars were inserted. The first $10-\mathrm{mm}$ trocar for a thoracoscope was placed between the posterior and mid-axillary line at the sixth intercostal space, and the other two ports to manipulate were located at the fourth intercostal space of the mid-axillary line, and the sixth intercostal space of the anterior axillary line, respectively.

Under the guidance of a thoracoscope, sheets of pleura and a wedge of lung with metastatic lesions were resected and/or thymectomy was performed first. A pericardium window was opened once having pericardial effusion. The hyperthermic perfusion system was then built up (Figure 2). Generally, in order to achieve adequate perfusion, the inflow catheter is placed at the port of the sixth intercostal space of the anterior axillary line, the outflow catheter at the fourth intercostal space of the mid-axillary line and

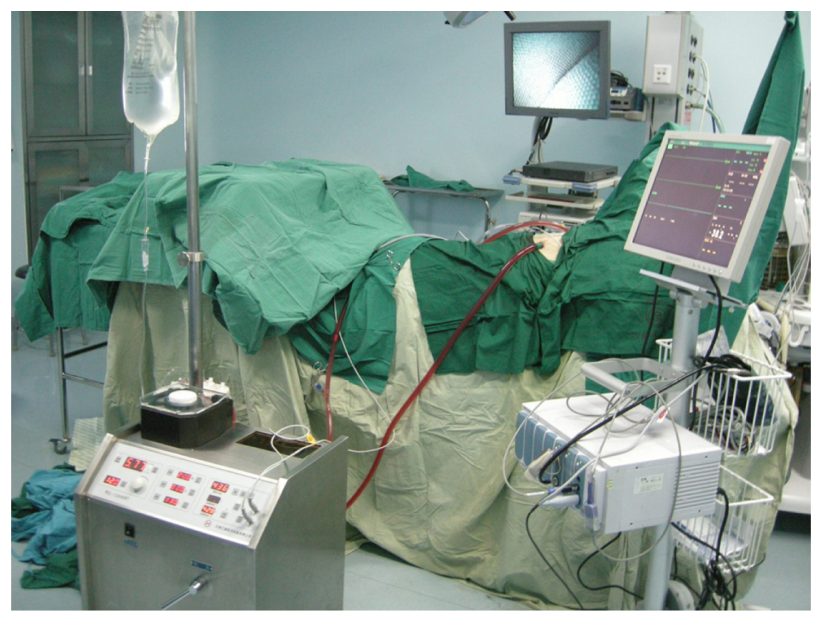

Figure 2 The hyperthermic perfusion system during surgery. 


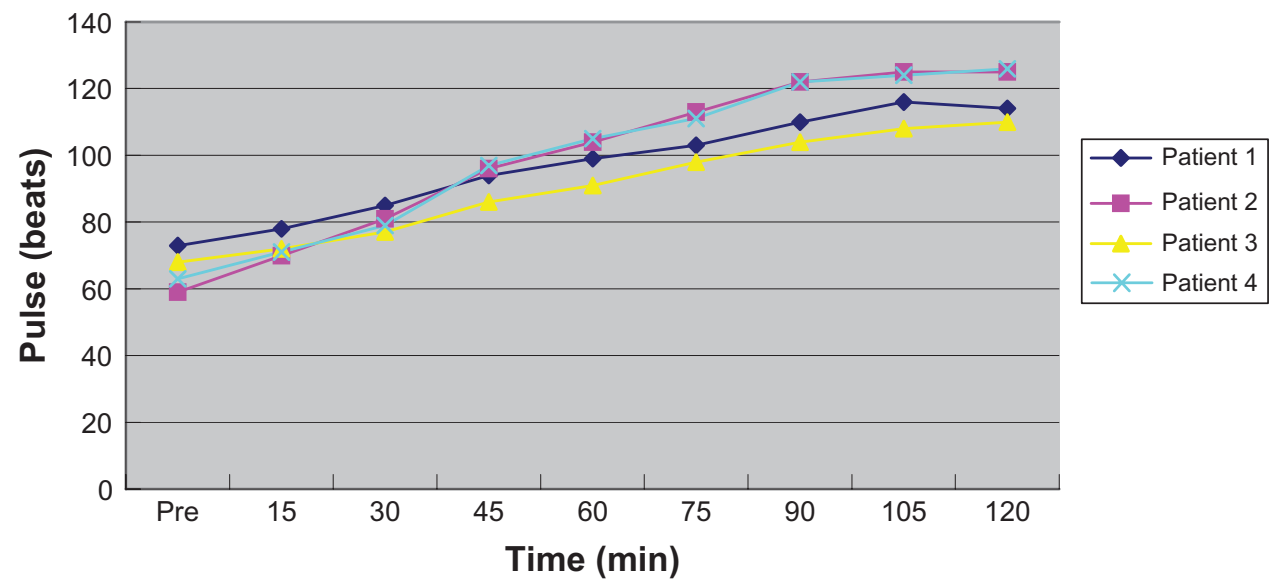

Figure 3 Changes in patients' pulse during surgery.

a temperature sensor at the port for the thoracoscope. All ports were sutured tightly after the hyperthermic perfusion system was set up.

Before the hyperthermic perfusion system was used, $0.9 \%$ normal saline $4500-5000 \mathrm{~mL}$ was heated to a temperature of $43^{\circ} \mathrm{C}$ to $44^{\circ} \mathrm{C}$ and $100 \mathrm{mg} / \mathrm{m}^{2}$ of cisplatin was added. The ipsilateral lung was deflated. The thoracic cavity was perfused at a speed of approximately $1.8-2.3 \mathrm{~L} / \mathrm{min}$ with $0.9 \%$ normal saline. The intrathoracic temperature remained between $42^{\circ} \mathrm{C}$ and $43^{\circ} \mathrm{C}$. The perfusion process lasted for 2 hours. During this period, changes of patient's core temperature and pulse were recorded. After surgery, a thoracic tube was placed in the apex and dorsal sinus.

Adjuvant radiation therapy for the ipsilateral thoracic cavity was needed 1 month after surgery. Such patients were not recommended to have postoperative chemotherapy if there was no evidence of other metastasis.

\section{Results}

There were no perioperative deaths. Changes in patients' core temperature and pulse during the hyperthermic perfusion are shown in Figures 3 and 4. Patients' core temperature varied from $36.3^{\circ} \mathrm{C}$ to $39.3^{\circ} \mathrm{C}$ and pulse from 59 beats/min to 126 beats/min. Temperature and pulse increased more substantially in two elderly patients than in relatively young patients. Intraoperative sinus tachycardia occurred in two elderly patients. No hematologic toxicity and nephrotoxicity was observed within 1 week after surgery. Postoperative pneumonia occurred in one elderly patient. No patients complained about nausea or vomiting after surgery. According to the 1999 World Health Organization histologic classification, ${ }^{2}$ the histologic subtypes of two patients' thymoma was type B2, the third was type AB, and the fourth type B3.

Patients were followed for 1-4 years and the outcomes are summarized in Table 1. One old patient died of heart failure 1 year after surgery. There were no patients with local recurrence (Figure 5) or metastases to distant site.

\section{Discussion}

The treatment for thymoma has evolved in recent decades. The long-term survival rate of patients with thymoma experiencing complete thymectomy in combination with

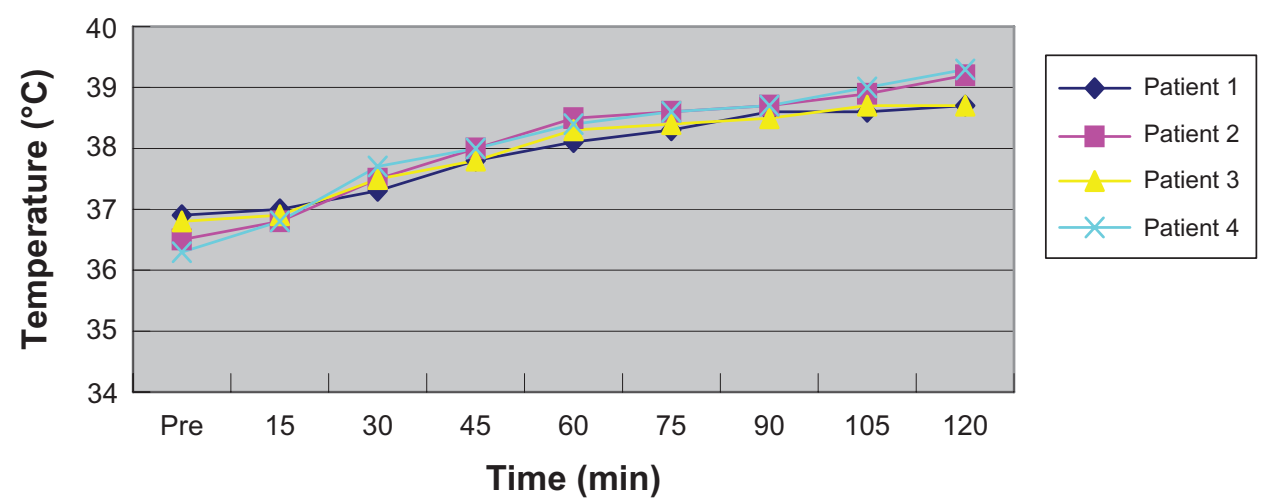

Figure 4 Changes in patients' core temperature during surgery. 

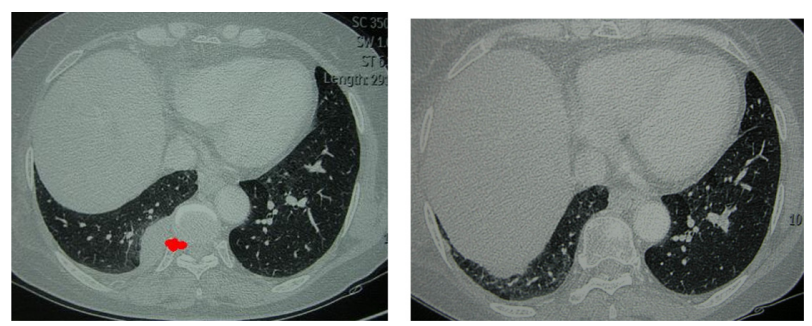

Figure $\mathbf{5}$ The patient with pleural metastases of thymoma shown by preoperative CT (right) and with no evidence of local recurrence showed by CT scan 1.5 years after surgery (left).

Abbreviation: CT, computed tomography.

postradiation therapy could optimally reach up to $75 \%$ after 10 years. ${ }^{3}$ But as noted previously, its local recurrent rates after surgery were $12 \%$ to $33 \%$ because of different stages of thymoma involved. ${ }^{4-6}$ It might be a result of perioperative seeding that recurrence of thymoma is frequently confined to pleural cavities opened during the primary surgery. ${ }^{7}$ No definitely curative therapy was introduced for this kind of pleural dissemination. Even radical resection seems to be impossible to achieve total surgical eradication. Due to thymoma's characteristics of slow growth and rare distant metastasis, surgical treatment combined with hyperthermic intrapleural chemotherapy may result in a good prognosis for patients with pleural metastases.

The efficacy of combination cytoreductive surgery and intraperitoneal hyperthermic perfusion was tested in the treatment of peritoneal surface malignancies for 2 decades..$^{8-10}$ Hyperthermia is cytotoxic and can inhibit DNA repair. Moreover, it has a synergistic cytotoxic effect in enhancing drug uptake in local tissue for some drugs, such as cisplatin. Issels et al's randomized trial showed that not only does regional hyperthermia increase the benefit of chemotherapy, but it also is safe and effective in experimental and clinical settings. ${ }^{11}$ Hyperthermic intrapleural chemotherapy makes the tumor expose directly to higher drug concentrations, meanwhile a lower incidence of side effects may be expected. Chemotherapy with regional hyperthermia may substantially improve local control compared with chemotherapy alone.

In recent years, there have been several centers in which hyperthermic intrapleural chemotherapy was used to control malignant pleural disease, such as mesothelioma. ${ }^{712-14}$ Thymoma with pleural or pericardial dissemination (Stage IVA) or pleural recurrence is relatively rare. There were case reports only on the use of hyperthermic intrapleural chemotherapy. ${ }^{7,15,16}$ The main concerns surrounding the technique are the outcome and side effects. In our study, only four patients were involved and followed up for 1-4 years
(Table 1). In addition to one death due to unrelated heart failure, there was no evidence of metastases to distant site or local recurrence in the other three patients. The temperature between $42^{\circ} \mathrm{C}$ and $43^{\circ} \mathrm{C}$ is considered to be efficacious in the treatment of patients with malignant neoplasms, but produces little risk of pulmonary edema..$^{17,18}$ In our study, our patients' core temperature varied from $36.3^{\circ} \mathrm{C}$ to $39.3^{\circ} \mathrm{C}$ and pulse from 59 beats $/ \mathrm{min}$ to 126 beats $/ \mathrm{min}$. There were no serious renal or hematologic side effects found.

Although this technique is not complicated and is relatively safe, attention should be paid to the selection of patients and monitoring of intrathoracic temperature, which may otherwise produce unexpected complications.

In conclusion, cytoreductive surgery and intrathoracic hyperthermic perfusion with chemotherapy may affect thymoma or thymic carcinoma with pleural dissemination and may have an encouraging impact on patients' long-term survival.

\section{Acknowledgments}

This study was supported by the International Union against Cancer (UICC) International Cancer Transfer (ICRETT) Fellowship. Dr Thomas A D'Amico, section chief of the Division of Cardiothoracic Surgery of Duke University Medical Center, assisted with drafting this paper.

\section{Disclosure}

The authors report no conflicts of interest in this work.

\section{References}

1. Ogawa K, Uno T, Toita T, et al. Postoperative radiotherapy for patients with completely resected thymoma: a multi-institutional, retrospective review of 103 patients. Cancer. 2002;94(5):1405-1413.

2. Rosai J. Histological typing of tumors of the thymus. In: World Health Organization International Histological Classification of Tumors, 2nd ed. New York, NY: Springer-Verlag; 1999.

3. Lucchi M, Ambrogi MC, Duranti L, et al. Advanced stage thymomas and thymic carcinomas: results of multimodality treatments. Ann Thorac Surg. 2005;79(6):1840-1844.

4. Ruffini E, Mancuso M, Oliaro A, et al. Recurrence of thymoma: analysis of clinicopathologic features, treatment, and outcome. J Thorac Cardiovasc Surg. 1997;113(1):55-63.

5. Verley JM, Silbert D, Hollmann KH, Levasseur P. Histopathology and prognosis of thymomas. Statistical analysis of 200 cases. Rev Mal Respir. 1988;5(2):179-185.

6. Lewis JE, Wick MR, Scheithauer BW, Bernatz PE, Taylor WF. Thymoma. A clinicopathologic review. Cancer. 1987;60(11):2727-2743.

7. de Bree E, van Ruth S, Baas P, et al. Cytoreductive surgery and intraoperative hyperthermic intrathoracic chemotherapy in patients with malignant pleural mesothelioma or pleural metastases of thymoma. Chest. 2002;121(2):480-487.

8. Kusamura S, Younan R, Baratti D, et al. Cytoreductive surgery followed by intraperitoneal hyperthermic perfusion: analysis of morbidity and mortality in 209 peritoneal surface malignancies treated with closed abdomen technique. Cancer. 2006;106(5):1144-1153. 
9. Deraco M, Casali P, Inglese MG, et al. Peritoneal mesothelioma treated by induction chemotherapy, cytoreductive surgery, and intraperitoneal hyperthermic perfusion. J Surg Oncol. 2003;83(3):147-153.

10. Ceelen WP, Hesse U, de Hemptinne B, Pattyn P. Hyperthermic intraperitoneal chemoperfusion in the treatment of locally advanced intra-abdominal cancer. Br J Surg. 2000;87(8):1006-1015.

11. Issels RD, Lindner LH, Verweij J, et al. Neo-adjuvant chemotherapy alone or with regional hyperthermia for localised high-risk soft-tissue sarcoma: a randomised phase 3 multicentre study. Lancet Oncol. 2010;11(6):561-570.

12. van Sandick JW, Kappers I, Baas P, Haas RL, Klomp HM. Surgical treatment in the management of malignant pleural mesothelioma: a single institution's experience. Ann Surg Oncol. 2008;15(6):1757-1764.

13. van Ruth S, Baas P, Haas RL, Rutgers EJ, Verwaal VJ, Zoetmulder FA. Cytoreductive surgery combined with intraoperative hyperthermic intrathoracic chemotherapy for stage I malignant pleural mesothelioma. Ann Surg Oncol. 2003;10(2):176-182.
14. de Bree E, van Ruth S, Schotborgh CE, Baas P, Zoetmulder FA. Limited cardiotoxicity after extensive thoracic surgery and intraoperative hyperthermic intrathoracic chemotherapy with doxorubicin and cisplatin. Ann Surg Oncol. 2007;14(10):3019-3026.

15. Iyoda A, Yusa T, Hiroshima K, Fujisawa T. Surgical resection combined with intrathoracic hyperthermic perfusion for thymic carcinoma with an intrathoracic disseminated lesion: a case report. Anticancer Res. 1999;19(1B):699-702.

16. Fukushima K, Sato T, Mitsuhashi S, et al. Isaacs' syndrome associated with myasthenia gravis, showing remission after cytoreductive surgery of pleural recurrence of thymoma. Neuromuscul Disord. 2006; 16(11):763-765.

17. Turano C, Ferraro A, Storm R. The biochemical mechanism of selective heat sensitivity of cancer cells. Eur J Cancer. 1970;6:67-72.

18. Mustafa KY, Selig WM, Borhop KE, Minnear FL, Malik AB Hyperthermia induced pulmonary edema. J Appl Physiol. 1986;60: 1980-1985.

\section{Publish your work in this journal}

OncoTargets and Therapy is an international, peer-reviewed, open access journal focusing on the pathological basis of all cancers, potential targets for therapy and treatment protocols employed to improve the management of cancer patients. The journal also focuses on the impact of management programs and new therapeutic agents and protocols on

\section{Dovepress}

patient perspectives such as quality of life, adherence and satisfaction The manuscript management system is completely online and includes a very quick and fair peer-review system, which is all easy to use. Visit http://www.dovepress.com/testimonials.php to read real quotes from published authors.

Submit your manuscript here: http://www.dovepress.com/oncotargets-and-therapy-journal 